\title{
Autosomal Dominant Spinocerebellar Ataxias: An Asian Perspective
}

\author{
E.K. Tan
}

JOURNALEXCHANGE. Published with permission from the Neurological Journal of South East Asia 2002;7:1-8

\begin{abstract}
Autosomal dominant cerebellar ataxias, frequently referred to as spinocerebellar ataxias (SCAs) have been under intense scientific research limelight since expansions of coded CAG trinucleotide repeats were demonstrated to cause several dominantly inherited SCAs. The number of new SCA loci has expanded dramatically in recent years. At least ten genes have been identified for SCAs 1, 2, 3, 6, 7, 8, 10, 12, 17, dentatorubral-pallidoluysian atrophy (DRPLA), and six loci responsible for SCAs 4, 5, 11,13, 14, and 16 have been mapped. Genetic testing is essential for diagnosis due to the overlapping and varied phenotypic features of the different SCAs. While there is no effective treatment available, genetic counseling is important for addressing the many ethical, social, legal, and psychological issues facing SCA patients. Researchers have recently provided valuable information on the pathogenesis of the disease and hopefully a cure will be available in the near future.
\end{abstract}

RÉSUMÉ: Ataxies spino-cérébelleuses autosomiques dominantes: situation en Asie. Les ataxies cérébelleuses autosomiques dominantes, souvent nommées ataxies spino-cérébelleuses (ASCs), ont suscité beaucoup d'intérêt dans le monde scientifique depuis la découverte qu'une expansion des répétitions du trinucléotide CAG est la cause de plusieurs ASCs dont l'hérédité est dominante. Le nombre de nouveaux loci ASC a augmenté rapidement dans les dernières années. Au moins dix gènes ont été identifiés pour les ASCs 1, 2, 3, 6, 7, 8, 10, 12, 17 et l'atrophie dentatorubro-pallidoluysienne (ADRPL) et six loci responsables des ASCs 4, 5, 11, 13, 14 et 16 ont été cartographiés. Le test génétique est essentiel au diagnostic parce que les caractéristiques phénotypiques des différentes ASCs sont variées et se recoupent. Bien qu'aucun traitement efficace ne soit disponible, le conseil génétique est important pour examiner les aspects éthiques, sociaux, légaux et psychologiques auxquels les patients sont confrontés. Les chercheurs ont fourni des informations précieuses sur la pathogenèse de la maladie et il est à espérer qu'un traitement soit bientôt disponible.

Can. J. Neurol. Sci. 2003; 30: 361-367

Autosomal dominant cerebellar ataxias (ADCAs) are a group of neurodegenerative diseases characterized by cerebellar dysfunction either alone or in combination with other neurological abnormalities. ${ }^{1-4}$

\section{Clinical Classification}

In the past, various authors have classified cerebellar degeneration based on neuropathologic differences. ${ }^{5}$ More recently, Anita Harding 6 proposed a clinical classification of cerebellar ataxias into; ADCA I: characterized by cerebellar syndrome with other neurologic involvement (such as pyramidal, extrapyramidal, ophthalamoplegia, dementia), ADCA II: cerebellar syndrome with pigmentary maculopathy, ADCA III: relatively pure cerebellar syndrome.

\section{GENETIC CLASSIFICATION}

Autosomal dominant cerebellar ataxias, frequently referred to as spinocerebellar ataxias (SCAs) have been under intense scientific research limelight since expansions of coded CAG trinucleotide repeats were demonstrated to cause several dominantly inherited SCAs. ${ }^{1-4}$ The number of new SCA loci has expanded dramatically in recent years. At least ten genes have

From the Department of Neurology, Singapore General Hospital, Singapore. Reprint requests to: E.K. Tan, Director, Parkinson's Disease and Movement Disorder Programme, Department of Neurology, Singapore General Hospital, Outram Road, Singapore 169608. Fax 652203321 E-mail: gnrtek@sgh.com.sg 
been identified for SCAs 1, 2, 3, 6, 7, 8, 10, 12, 17, dentatorubralpallidoluysian atrophy (DRPLA), and six loci responsible for SCAs $4,5,11,13,14$, and 16 have been mapped ${ }^{7-23}$ (Table). In SCAs $1,2,3,6,7$, the mutation is due to CAG repeat expansions within the coding regions of the gene. SCA 8 is associated with an expansion of a CTG repeat in the 3'untranslated region (UTR) of the $S C A 8$ gene that produces antisense mRNA to the KLHL1 gene on the complementary strand. In SCA 10, the diseasecausing expansion occurs in the ATTCT pentanucleotide repeat of intron 9 of $S C A 10$, a gene of unknown function widely expressed in the brain. In SCA12 there is an expanded CAG repeat in the 5, untranslated region (UTR) of $P P P 2 R 2 B$, a gene coding for a brain-specific regulatory subunit of the protein phosphatase PP2A. Episodic ataxia types 1 and 2 (EA-1 and EA-2) are also dominantly inherited cerebellar ataxias caused by point mutations within a voltage-gated potassium channel gene (KCNAl) and the cerebral P/Q-type calcium channel alpha 1 subunit gene (CACNL1A4), respectively. ${ }^{24,25}$ SCA 17 is due to an expanded $\mathrm{CAG}$ repeat in TATAbox binding protein $(T B P)$ gene which gives rise to an elongated polyglutamine tract in the respective proteins. As a result of these discoveries, a new classification based on the genetic loci of the SCAs has developed. These loci have been numbered based on their order of classification. However, a locus for SCA 9 has yet to be assigned. Based on Harding's classification, SCAs 1, 2, 3, 4, 8, 12 would be under ADCA I, SCA 7 under ADCA II, and SCAs 5, 6, 10, 11, 14, 16 under ADCA III.

\section{Prevalence of SPInocerebellar ataxia}

It is difficult to ascertain with great accuracy the true prevalence of the different subtypes of SCAs because most published studies focused on clinic-based populations and hence their findings were subjected to referral bias. Thus the true prevalence of some late onset SCAs may be underestimated. However, based on available information, SCAs 1, 2 and 3 account for more than half of the ADCAs tested in the world. SCA 3/Machado-Joseph disease (MJD), originally described in two MJD families of Azorean descent, has been found in different ethnic populations and appears to be most common in many countries including United States and Germany. SCA 1 and SCA 2 are more common in the United Kingdom and Italy, and SCA 2 in Cuba. SCA 10 has been seen only in Mexicans. DRPLA is rare outside Japan. SCAs 12, 13, and 14 have been reported in German, American, French and Japanese families, respectively. For some countries such as Italy, founder effects may explain why certain SCAs predominate in specific regions of the country. ${ }^{26-32}$

\section{Prevalence of SCAs in Asian countries}

Relative to the West, there is a paucity of information of SCAs in Asian countries. Most of the published data are from Japan, China, India and South Korea. ${ }^{32-59}$ One of the major reasons is the lack of facilities and expertise in diagnosing SCAs in many countries in Asia. The absence of an effective curative treatment does not encourage health authorities to grant priority to develop diagnostic SCA capability in places where provision of basic healthcare is more important.

\section{Japan}

SCAs 3 and 6 appear common in a number of areas in Japan. ${ }^{33,36}$ In a study in Hokkaido, the northernmost island of Japan, the authors found that out of 155 unrelated SCAfamilies, $23.9 \%$ was positive for SCA3, $29.0 \%$ for SCA6, 9.7\% for SCA $1,7.7 \%$ for SCA 2 , and $2.6 \%$ for DRPLA. ${ }^{36}$ However, none of their patients were screened positive for SCA 7 and SCA 8. A total of $27.1 \%$ of the patients had still unknown SCAmutations.

Table: Genetic classification of autosomal dominant cerebellar ataxias

\begin{tabular}{|c|c|c|c|c|c|c|}
\hline Type & Locus & Mutation & $\begin{array}{l}\text { Normal } \\
\text { repeats size }\end{array}$ & $\begin{array}{l}\text { Abnormal } \\
\text { repeat size }\end{array}$ & $\begin{array}{l}\text { Cryptic } \\
\text { Interruptions }\end{array}$ & $\begin{array}{l}\text { Intergenerational } \\
\text { expansions }\end{array}$ \\
\hline SCA 1 & $6 \mathrm{p}$ & CAG & $6-44$ & $39-82$ & 1-3 CAT & $\mathrm{p}>\mathrm{m}$ \\
\hline SCA 2 & $12 q$ & CAG & $14-31$ & $33-64$ & CAA & $\mathrm{p}>\mathrm{m}$ \\
\hline SCA 4 & $16 \mathrm{q}$ & $?$ & $?$ & $?$ & - & $?$ \\
\hline SCA 5 & 11 cen & $?$ & $?$ & $?$ & - & $?$ \\
\hline SCA 6 & $19 \mathrm{P}$ & CAG & $4-18$ & $20-30$ & - & No \\
\hline SCA 8 & $13 q$ & CTG & $16-91$ & $107-127$ & - & $\mathrm{m}>\mathrm{p}$ \\
\hline SCA10 & $22 \mathrm{q}$ & ATTCT & $10-22$ & $1000-4500$ & - & $?$ \\
\hline SCA 11 & $15 \mathrm{q}$ & $?$ & $?$ & $?$ & - & $?$ \\
\hline SCA12 & $5 q$ & CAG & $<29$ & $66-78$ & - & $?$ \\
\hline SCA13 & $19 q$ & $?$ & $?$ & $?$ & - & $?$ \\
\hline SCA14 & $19 \mathrm{q}$ & $?$ & $?$ & $?$ & - & $?$ \\
\hline
\end{tabular}

p:paternal, m:maternal, SCA9 is not assigned, SCA15 assigned to an Australian kindred but no linkage analysis done yet 
A founder effect of SCA6 was observed in the Chugoku area of Western Japan. ${ }^{33}$ In the Tottori prefecture, located in the northeastern part of the Chugoku district, there was a cluster of SCA 6 families within the eastern area. Genotyping with DNA microsatellite markers linked to the CACNL1A4 gene on chromosome 19p13 demonstrated shared allelic characteristics and revealed a common haplotype in the majority of Japanese families. In another study involving 117 unrelated SCA families that originated from the Tohoku District in the northernmost part of Honshu Island in Japan, the SCA 1 mutation was found to be the most frequent $\left(24.8 \%\right.$ of all such families). ${ }^{34}$ The relative prevalence of SCA 1 in the Tohoku District is very high compared to other countries. As the population of this area seldom moved, the alleles with SCA 1 mutations are thought to have been present in this area for a long time.

Recently, in a community-based prevalence study involving 613,349 inhabitants in Tottori prefecture, Japan, 109 SCA patients were identified. ${ }^{32}$ The prevalence of SCA was 17.8 per 100,000 individuals. The most common was SCA 6 (25\%), followed by SCA1 (15\%), SCA3 (5\%) and DRPLA(5\%). None of the expanded alleles was found for SCA 2 and SCA 7. Prevalences per 100,000 individuals were: SCA 6, 2.40; SCA 1, 0.48; DRPLA, 0.32, and SCA3, 0.16. SCA14 was assigned to a Japanese SCA family. ${ }^{35}$ The authors performed linkage analysis in a three-generation Japanese family with a locus or mutation that differed from those of known SCAs. Multipoint analysis and haplotype reconstruction traced this novel spinocerebellar ataxia locus (SCA 14) to a 10.2-cM interval flanked by D19S206 and D19S605 on chromosome 19q13.4-qter. The family members with a late onset exhibited pure cerebellar ataxia, whereas those with an early onset first showed intermittent axial myoclonus followed by ataxia.

\section{China and Taiwan}

SCA 3 are most among Chinese from China and Taiwan. ${ }^{40-45}$ In a large study of 85 autosomal dominant SCAs families and 37 patients with sporadic SCAin China, SCA1 was found in $4.70 \%$, SCA 2, 5.88\% and SCA 3 48.23\%. Sixty-five patients from 35 kindreds $(41.19 \%)$ and 37 patients with sporadic SCA did not test positive for SCA 1, SCA 2, SCA 3/MJD, SCA 6, SCA 7, or DRPLA. $^{43}$ SCA 2 was found in two Chinese patients with familial parkinsonism. Functional imaging revealed reduction of ${ }^{18} \mathrm{~F}$-dopa distribution in both the putamen and caudate nuclei. ${ }^{39}$

\section{India}

SCA2 appears common in India. ${ }^{51-53}$ One group analysed the SCA 1, SCA 2, SCA 3, SCA 6, SCA 7 and DRPLA loci for expansion of $\mathrm{CAG}$ repeats and detected $\mathrm{CAG}$ repeat expansion and found SCA1 to be present in $10.5 \%$, SCA2 in $17.5 \%$, SCA 3 in $7 \%$, and SCA6 in $1.8 \%$. No mutations were detected in the SCA 7 and DRPLA loci. ${ }^{51}$ In another study, 77 Indian families with autosomal dominant cerebellar ataxia phenotype were examined and SCA 12 was found in five families, which included a total of six patients and 21 family members. The sizes of the expanded alleles ranged from 55 to 69 CAG repeats, and the sizes of the normal alleles ranged from 7 to 31 repeats. ${ }^{48}$ The authors suggest that SCA 12 may not be as rare in some populations as previously thought.

\section{South Korea}

In the largest published study in this country, the frequency of six types of SCAs in 87 unrelated Korean patients with progressive ataxia were examined. SCA2 was the most frequent hereditary ataxia (12.6\%) and types 3 and 6 accounted for $4.6 \%$ and $6.9 \%$ of ataxia patients, respectively. DRPLA was found in three patients $(3.4 \%)$. SCAs 1 or 7 were not detected. DRPLA should be considered in Korean patients who present with progressive ataxia. ${ }^{59}$

\section{Singapore}

SCA 3 is most common in Singapore, followed by SCAs 1 and $2 .{ }^{60}$ Our preliminary observations suggest that in Singaporean Malays and Indians, SCA 2 should be considered, whereas in Singapore Chinese SCA3 is more prevalent.

\section{GENOTYPIC FEATURES}

SCAs generally share the following features. Firstly, anticipation, where there is progressive increase of expanded CAG repeats in successive generations. Those with larger CAG repeats display earlier ages of onset with greater disease severity than those with relatively smaller repeats. Secondly, there appears a critical size of repeat for most of the SCAs, above which the disease would manifest. Thirdly, influences of parental origin on repeat size instability. Paternal transmission of many SCAs (such as SCAs 1, 2, and 3) may result in a severe, rapidly progressive phenotype at a young age. This observation is also well-recognised in SCA7 in which increased embryonic lethality in paternal transmission has been postulated. ${ }^{61}$

Not all SCAs display the above characteristics. For example, in some SCAs, the disease and normal allele sizes overlap in an intermediate range. Alleles in the intermediate range show reduced penetrance in SCA2. In SCA7, the intermediate alleles do not cause disease but can give rise to de novo expansion to disease causing size in subsequent generations. Some SCAs (such as SCAs 1 and 2) have non-CAG repeat (CAA, CAT) interruptions. The CAT interruptions introduce histidines in the polyglutamine tract in the protein product, ataxin 1 , that may prevent pathogenicity of expanded polyglutamines in SCA 1. The presence of the CAT interruptions on normal alleles is useful for distinguishing normal from diseased alleles for allele sizes of 36-44. The clinical relevance of somatic mosacism seen in some SCAs $(1,3$, and 7$)$ is unclear. SCA8 exhibits instability of repeat with a bias towards expansion in maternal transmission and frequent contraction in paternal transmission. SCAs 1, 2, 3 and 7 may show length changes during intergenerational transmission with a predisposition to expansion in subsequent generations. While anticipation has been reported for SCA6, the CAG repeat size shows no size instability in parent-to-child transmission. SCAs 1, 2, 3, 5, 10 and 14 also show anticipation, whereas SCAs 8,12 and 13 do not.

\section{Phenotypic features}

There is a wide phenotypic overlap amongst the SCAs and inter-familial and intra-familial phenotypic variability exists even for each SCA subtype. However, there are some characteristic features of each SCA. For SCA 1, there is hypermetric saccades and hyperreflexia. Markedly reduced 
velocity of saccadic eye movements, areflexia and changes similar to those seen in olivopontocerebellar atrophy on brain imaging suggest SCA2. For MJD/SCA3, combinations of protruded eyes, muscle fasciculations, spasticity, chorea, gaze-evoked nystagmus, parkinsonism and peripheral neuropathy are characteristic features. However, SCA1 and SCA2 also share a number of these features. For SCA 4, there is sensory neuropathy in addition to cerebellar ataxia. SCA7 is distinguished by macular degeneration. SCAs 5, 6, 10 and 11 should be considered in patients with relatively pure cerebellar signs. In SCA6, there is frequently a lack of family history and late age of onset of symptoms. SCA 8 patients have a mild sensory neuropathy with frequent late onset spasticity. Patients with SCA 13 characteristically show slowly progressive cerebellar ataxia of early childhood onset with mild mental retardation and motor developmental delay. SCA 14 patients have early onset myoclonus. Head and hand tremors are frequently seen in SCA16, whereas intellectual deterioration and dysphagia are seen in SCA17. There are some overlapping clinical features between SCA 6 and patients with EA-2 and familial hemiplegic migraine. The CAG expansion in SCA 6 is located in the alpha-1Avoltage-dependent calcium channel gene and EA-2 is caused by a point mutation in the same gene. If there is a history of seizures with ataxia, DRPLA and SCA 10 need to be considered. For SCA 10, seizures are accompanied by relatively pure cerebellar ataxia. SCA 3 and DRPLA need to be considered in suspected Huntington's disease (HD) patients if HD DNAtest is negative. Some SCA 2 and SCA 3 patients may show pure parkinsonian phenotype.

Our experience suggests that the predictive value of some of these characteristic clinical features may increase when applied to a particular ethnic population where the most common SCA subtypes are known. This is illustrated by our recent study, ${ }^{60}$ where we determined the prevalence of SCA subtypes and predictive features of a positive DNA test in consecutive, clinically diagnosed SCA cases in Singapore. Twenty-one consecutive patients from 14 families were evaluated. Thirteen patients $(61.9 \%)$ from six families had a positive DNA test. Eleven of these (all ethnic Chinese) had SCA 3 (abnormal CAG size ranged from 61 to 71), and two ethnic Malays had SCA 2 (abnormal CAG size of 39). Clinical features, which were highly predictive of a positive DNA SCA test in our population, included presence of a positive family history, chorea and dystonia, muscle and tongue fasciculations, gaze-evoked nystagmus, and hypertonia. Our study draws attention to the observation that knowledge of relatively specific features of the most common SCA subtype in a local population can greatly enhance the practical accuracy of the choice of which SCADNA test to order.

\section{Pathogenesis}

The gene products of SCA genes are designated ataxins. Ataxin 1, the product of SCA 1 gene is probably the most intensively studied, since the transgenic SCA 1 mouse model was the first developed. The normal function of proteins with glutamine repeats is not entirely clear, though these proteins have been postulated to be responsible for development, neurogenesis or transcriptional activities. ${ }^{2}$ Overexpression of a mutant SCA 1 allele in mice resulted in progressive ataxia and Purkinje cell degeneration. However, in mice with targeted deletion of SCA 1 gene, no ataxia or neurodegeneration were noted. These observations support the theory that SCA 1 mutation causes disease via a toxic gain of function mechanism. ${ }^{62-64}$

The ataxins are transported from the cytoplasm to the nucleus where they aggregate and form intranuclear inclusions (NII). NI have been demonstrated in SCAs 1, 2, 3 and 7. ${ }^{65-67}$ However, there appears to be no correlation between the distribution of NII and sites of pathology. For instance, NII are distributed in sites of brain involvement in SCA 1 and 3, but the cerebellum is spared in SCA2. Immunohistological studies suggest that NI are ubiquitin positive and various components of the proteosomes appear to interact with them. ${ }^{68}$ This implies that the expanded ataxins are targets for the ubiquitin-proteosome proteolyitic machinery. Aggregates of ataxin 1 stain positively for the molecular chaperone HDJ-2/HSDJ suggesting that protein misfolding causes the NII in SCA 1 . In vitro studies show that there is decreased ataxin 1 aggregation when HDJ-2/HSDJ is overexpressed. HDJ-2/HSDJ may promote recognition of the expanded or aberrant polyglutamine tract resulting in early ubiquitin-proteosome degradation or promote refolding. ${ }^{69}$ Thus it appears that a chaperone stress response is being mounted to handle the toxic presence of misfolded polyglutamine proteins.

There was a lot of excitement initially when NI were first described in SCAfor it was thought that preventing NI formation would prevent disease formation. However, there is increasing evidence that the mere formation of NI is not the most critical step in cell dysfunction. This is based on the poor correlation between distribution of NII and the sites of pathology. Furthermore, in vitro studies have demonstrated that increased formation of NI do not promote cell death. ${ }^{69}$ It does appear that NII represents the "scars" (similar to Lewy bodies in patients with Parkinson's Disease) of damage that had already occurred. On the other hand, nuclear localisation of the expanded ataxins appear important for pathogenesis for it has been demonstrated in transgenic SCA1 mice models that prevention of transport of ataxins into the nucleus prevents formation of the disease. ${ }^{70}$ Based on available evidence, one hypothesis of a possible chain of events which lead to cell dysfunction include: firstly, changes in the tertiary structure of the ataxins due to expansion of the polyglutamine tracts; secondly, aberrant interactions with the abnormal ataxins; thirdly, transport of ataxins to nuclei of certain cells depending on the cell-specific protein interactions; fourthly, aggregation (involving the proteosome complex and molecular chaperones) of the ataxins as NII.

\section{Clinical IMPLiCATIONS}

Genetic testing of SCAs has a number of potential clinical roles. First, confirmation of diagnosis allows early institution of genetic counseling. Second, it enables genotype-phenotype correlation. Third, it helps select specific patients for clinical drug trails. Fourth, it leads to better understanding of pathogenesis and long-term clinical outcome of the disease.

At present, DNA testing can directly detect mutations for SCAs 1, 2, 3, 6, 7, 8, 10, 12 and 17 and DRPLA. As the list of these DNAtests grows, the variable and overlapping phenotypic manifestations of the SCAsubtypes make it difficult to select the specific SCA DNA test. We recommend an initial screen for 
SCAs 1, 2 and 3 to be carried out in suspected cases as they make up the majority of dominantly inherited SCAs. If these are negative, screening can be carried out for the other SCAs. In some cases, the ethnic origin and the presence of certain suggestive clinical signs should provide some guidance. For instance, if seizures accompany ataxia, DRPLA and SCA 10 should be screened first.

To be cost-effective, these tests should be done in SCAs that demonstrate a clear mode of inheritance. For those without family history, secondary causes such as Wilson's disease and hypothyroidism should be first excluded. If the family history is unreliable or ambiguous, testing in apparent 'sporadic' cases is useful, for some sporadic cases have been found to be autosomal dominant. This is particularly relevant in Asian populations for, based on our experience, some patients may feel that their disease is a "curse" and may not be willing to volunteer information regarding their family members. At-risk family members may also not want to be associated with their affected relatives and decline genetic testing. Patients with SCA 6 may not always give a positive history since disease onset is usually late. A de novo mutation may cause the disease with clearly negative family history. Early parental deaths, non-paternity, and adoption are also important factors to consider. If all available SCA screens are unyielding, it is worthwhile considering other diseases which can mimic the SCA phenotype such as adrenoleukodystrophy and multiple system atrophy. ${ }^{71}$

There are presently no standard guidelines for SCA testing. However, the importance of genetic counseling cannot be overemphasized. Like other neurodegenerative diseases without a definitive cure, there are a number of ethical, social, legal and psychological issues to consider for SCAgenetic testing. ${ }^{72}$ These include confirmatory testing, prenatal diagnosis, predictive testing and asymptomatic testing for children, confidentiality, insurability, finances, employment, disability, and marriage. Most clinicians would agree that testing in at-risk asymptomatic children is not encouraged. Prenatal testing of SCAs is also available. However issues such as possible termination of pregnancy and follow-up care for psychological problems require careful management by a combined team of experts including the physicians, genetic counselors, psychologists and social workers.

\section{FUTURE DIRECTIONS}

Clinical drug trials for SCAs have been disappointing. Treatment has been symptomatic though antioxidants and NMDA antagonists have been used in the hope of preventing further neurodegeneration. ${ }^{73}$ On the brighter side, great strides have been made in our understanding of the pathogenesis of the disease. One common theme has emerged in the pathogenesis of SCAs (whether polyglutamine disease or not): there are specific cellular proteins or components that interact with the mutant ataxins which influence its degradation and subcellular distribution. Identification of such proteins and designing drugs to intervene in these interactions may prevent or slow down the disease.

\section{ADDENDUM}

Five additional SCA loci have been determined since this paper was written. Some guidelines for genetic testing of inherited movement disorders (including SCAs) have been proposed by a Movement Disorders Society task force. ${ }^{74}$

\section{ACKNOWLEDGEMENTS}

The author thanks the many SCAfamilies for their cooperation and support, and Prof Wong Meng Cheong, Drs Ivy Ng, Law Hai Yang, Zhao $\mathrm{Yi}$ and Tetsuo Ashizawa. Our work is supported by grants from the Department of Clinical Research, Singapore General Hospital.

\section{REFERENCES}

1. Tan EK, Ashizawa T. Genetic testing in spinocerebellar ataxia: defining a clinical role. Arch Neurol 2001;58:191-195.

2. Wells RD, Warren ST. Genetic instabilities and hereditary neurological diseases. Academic Press 1998.

3. Subramony SH, Filla A. Autosomal dominant spinocerebellar ataxias ad infinitum? Neurology 2001;56:287-289.

4. Klockgether T, Wullner U, Spauschus A, Evert B. The molecular biology of the autosomal dominant cerebellar ataxias. Mov Disord 2000;15:604-612.

5. Holmes G. An attempt to classify cerebellar disease, with a note on Marie's hereditary ataxia. Brain 1907;30:545-567.

6. Harding AE. Clinical features and classification of inherited ataxias. Adv Neurol 1993; 61:1-14.

7. Orr HT, Chung M, Banfi S, et al. Expansion of an unstable trinucleotide CAG repeat in spinocerebellar ataxia type 1 . Nat Genet 1993;4:221-226.

8. Pulst SM, Nechiporuk A, Nechiporuk T, et al. Moderate expansion of a normally biallelic trinucleotide repeat in spinocerebellar ataxia type 2. Nat Genet 1996;14:269-276.

9. Imbert G, Saudou F, Yvert G, et al Cloning of the gene for spinocerebellar ataxia 2 reveals a locus with high sensitivity to expanded CAG/glutamine repeats. Nat Genet 1996;14: 285291.

10. Geschwind DH, Perlman S, Figueroa CP, Treiman LJ, Pulst SM. The prevalence and wide clinical spectrum of the spinocerebellar ataxia type 2 trinucleotide repeat in patients with autosomal dominant cerebellar ataxia. Am J Hum Genet 1997;60: 842-850.

11. Kawaguchi Y, Okamoto T, Taniwaki M, et al. CAG expansions in a novel gene for Machado-Joseph disease at chromosome 14q32.1. Nat Genet 1994;8:221-228.

12. Flanigan K, Gardner K, Alderson K, et al. Autosomal dominant spinocerebellar ataxia with sensory axonal neuropathy (SCA4): clinical description and genetic localization to chromosome 16q22.1. Am J Hum Genet 1996;59:392-399.

13. Ranum LP, Schut LJ, Lundgren JK, Orr HT, Livingston DM. Spinocerebellar ataxia type 5 in a family descended from the grandparents of President Lincoln maps to chromosome 11. Nat Genet 1994;8:280-284.

14. Zhuchenko O, Bailey J, Bonnen P, et al. Autosomal dominant cerebellar ataxia (SCA6) associated with small polyglutamine expansions in the alpha (1A)-voltage-dependent calcium channel. Nat Genet 1997;15:62-69.

15. David G, Abbas N, Stevanin G, et al. Cloning of the SCA7 gene reveals a highly unstable CAG repeat expansion. Nat Genet 1997; 17: 65-70.

16. Koob MD, Moseley ML, Schut LJ, et al. An untranslated CTG expansion causes a novel form of spinocerebellar ataxia (SCA8). Nat Genet 1999;21:379-384.

17. Matsuura T, Yamagata T, Burgess DL, et al. Large expansion of ATTCT pentanucleotide repeat in spinocerebellar ataxia type 10 . Nat Genet 2000;26:191-194.

18. Worth PF, Giunti P, Gardner-Thorpe C, et al. Autosomal dominant cerebellar ataxia type III: linkage in a large British family to a $7.6 \mathrm{cM}$ region on chromosome $15 \mathrm{q} 14-21.3$. Am J Hum Genet 1999;65:420-426.

19. Holmes SE, O'Hearn EE, Mcinnis MG, et al. Expansion of a novel CAG trinucleotide repeat in the 5' region of PPP2R2B is associated with SCA12. Nat Genet 1999;23:391-392.

20. Herman-Bert A, Stevanin G, Netter J-C, et al. Mapping of 
spinocerebellar ataxia 13 to chromosome $19 \mathrm{q} 13.3-\mathrm{q} 13.4$ in a family with autosomal dominant cerebellar ataxia and mental retardation. Am J Hum Genet 2000;67:229-235.

21. Yamashita I, Sasaki H, Yabe I, et al. A novel locus for dominant cerebellar ataxia (SCA14) maps to a 10.2-cM interval flanked by D19S206 and D19S605 on chromosome 19q13.4-qter. Ann Neurol 2000;48:156-163.

22. Miyoshi Y, Yamada T, Tanimura M, et al. A novel autosomal dominant spinocerebellar ataxia (SCA16) linked to chromosome 8q22.1-24.1. Neurology 2001;57:96-100.

23. Nakamura K, Jeong SY, Uchihara T, et al. SCA 17, a novel autosomal dominant cerebellar atxia caused by an expanded polyglutamine in TATA-binding protein. Hum Mol Genet 2001;10:1441-1448.

24. Browne DL, Gancher ST, Nutt JG, et al. Episodic ataxia/myokymia syndrome is associated with point mutations in the human potassium channel gene, KCNA1. Nat Genet 1994;8:136-140.

25. Ophoff RA, Terwindt GM, Vergouwe MN, et al. Familial hemiplegic migraine and episodic ataxia type- 2 are caused by mutations in the $\mathrm{Ca} 2+$ channel gene CACNL1A4. Cell 1996;87:543-552.

26. Matsuura T, Ranum LP, Volpini V, et al. Spinocerebellar ataxia type 10 is rare in populations other than Mexicans. Neurology 2002;58:983-984.

27. Higgins JJ, Nee LE, Vasconcelos O, et al. Mutations in American families with spinocerebellar ataxia (SCA) type 3: SCA3 is allelic to Machado-Joseph disease. Neurology 1996;46:208-213.

28. Pareyson D, Gellera C, Castellotti B, et al. Clinical and molecular studies of 73 Italian families with autosomal dominant cerebellar ataxia type I: SCA1 and SCA2 are the most common genotypes. J Neurol 1999;246:389-393.

29. Filla A, De Michele G, Santoro L, et al. Spinocerebellar ataxia type 2 in southern Italy: a clinical and molecular study of 30 families. J Neurol 1999;246:467-471.

30. Schols L, Amoiridis G, Epplen JT, et al. Relations between genotype and phenotype in German patients with the Machado-Joseph disease mutation. J Neurol Neurosurg Psychiatry 1996;61:466470.

31. Leggo J, Dalton A, Morrison PJ, et al. Analysis of spinocerebellar ataxia types $1,2,3$, and 6 , dentatorubral-pallidoluysian atrophy, and Friedreich's ataxia genes in spinocerebellar ataxia patients in the UK. J Med Genet 1997;34:982-985.

32. Mori M, Adachi Y, Kusumi M, Nakashima K. A genetic epidemiological study of spinocerebellar ataxias in Tottori prefecture, Japan. Neuroepidemiology 2001;20:144-149.

33. Mori M, Adachi Y, Kusumi M, Nakashima K. Spinocerebellar ataxia type 6: founder effect in Western Japan. J Neurol Sci 2001;185:43-47.

34. Onodera Y, Aoki M, Tsuda T, et al. High prevalence of spinocerebellar ataxia type 1 (SCA1) in an isolated region of Japan. J Neurol Sci 2000;178:153-158.

35. Yamashita I, Sasaki H, Yabe I, et al. A novel locus for dominant cerebellar ataxia (SCA14) maps to a 10.2-cM interval flanked by D19S206 and D19S605 on chromosome 19q13.4-qter. Ann Neurol 2000;48:156-163

36. Sasaki H, Yabe I, Yamashita I, Tashiro K. Prevalence of triplet repeat expansion in ataxia patients from Hokkaido, the northernmost island of Japan. J Neurol Sci 2000;175:45-51.

37. Ikeda Y, Shizuka M, Watanabe M, Okamoto K, Shoji M. Molecular and clinical analyses of spinocerebellar ataxia type 8 in Japan. Neurology 2000;54:950-955.

38. Seto M, Tsujihata M. Cluster of Machado-Joseph disease in a small rural town near Nagasaki City, Japan: clinical and genetic studies of two families. J Neurol 1999;246:405-407.

39. Shan DE, Soong BW, Sun CM, et al. Spinocerebellar ataxia type 2 presenting as familial levodopa-responsive parkinsonism. Ann Neurol 2001;50:812-815

40. Soong BW, Lu YC, Choo KB, Lee HY. Frequency analysis of autosomal dominant cerebellar ataxias in Taiwanese patients and clinical and molecular characterization of spinocerebellar ataxia type 6. Arch Neurol 2001;58:1105-1109.

41. Zhou YX, Qiao WH, Gu WH, et al. Spinocerebellar ataxia type 1 in
China: molecular analysis and genotype-phenotype correlation in 5 families. Arch Neurol 2001;58:789-794.

42. Gu W, Wang Y, Liu X, et al. Molecular and clinical study of spinocerebellar ataxia type 7 in Chinese kindreds. Arch Neurol 2000;57:1513-1518

43. Tang B, Liu C, Shen L, et al. Frequency of SCA1, SCA2, SCA3/MJD, SCA6, SCA7, and DRPLA CAG trinucleotide repeat expansion in patients with hereditary spinocerebellar ataxia from Chinese kindreds. Arch Neurol 2000;57:540-554.

44. Cai T, Yu P, Chen X, Lopa M. Trinucleotide repeat expansion of spinocerebellar ataxia (SCA1) found in a Chinese family. Chin Med J (Engl) 1998;111:160-162.

45. Tang B, Wang D, Xia J. SCA1, SCA2, MJD/SCA3 (CAG)n mutation detection and analysis in patients with hereditary spinocerebellar ataxia from Chinese families. Zhonghua Yi Xue Za Zhi 1997:77:819-822.

46. Zhou YX, Wang GX, Tang BS, et al. Spinocerebellar ataxia type 2 in China: molecular analysis and genotype-phenotype correlation in nine families. Neurology 1998;51:595-598.

47. Hsieh M, Tsai HF, Lu TM, et al. Studies of the CAG repeat in the Machado-Joseph disease gene in Taiwan. Hum Genet 1997; 100:155-162.

48. Srivastava AK, Choudhry S, Gopinath MS, et al. Molecular and clinical correlation in five Indian families with spinocerebellar ataxia 12. Ann Neurol 2001;50:796-800.

49. Gangopadhyay PK, Ghosh B, Roy T, et al. Spinocerebellar ataxia type 6. J Assoc Physicians India 2001;49:658-659.

50. Fujigasaki H, Verma IC, Camuzat A, et al. SCA12 is a rare locus for autosomal dominant cerebellar ataxia: a study of an Indian family. Ann Neurol 2001;49:117-121.

51. Basu P, Chattopadhyay B, Gangopadhaya PK, et al. Analysis of CAG repeats in SCA1, SCA2, SCA3, SCA6, SCA7 and DRPLA loci in spinocerebellar ataxia patients and distribution of CAG repeats at the SCA1, SCA2 and SCA6 loci in nine ethnic populations of eastern India. Hum Genet 2000;106:597-604.

52. Saleem Q, Choudhry S, Mukerji M, et al. Molecular analysis of autosomal dominant hereditary ataxias in the Indian population: high frequency of SCA2 and evidence for a common founder mutation. Hum Genet 2000;106:179-187.

53. Pang J, Allotey R, Wadia N, et al. A common disease haplotype segregating in spinocerebellar ataxia 2 (SCA2) pedigrees of diverse ethnic origin. Eur J Hum Genet 1999;7(7):841-845.

54. Wadia N, Pang J, Desai J, et al. A clinicogenetic analysis of six Indian spinocerebellar ataxia (SCA2) pedigrees. The significance of slow saccades in diagnosis. Brain 1998;121(Pt 12):2341-2355.

55. Giunti P, Sweeney MG, Harding AE. Detection of the MachadoJoseph disease/spinocerebellar ataxia three trinucleotide repeat expansion in families with autosomal dominant motor disorders, including the Drew family of Walworth. Brain 1995;118(Pt 5): 1077-1085.

56. Koh SH, Kim HT, Kim SH, et al. Spinocerebellar ataxia type 6 and episodic ataxia type 2 in a Korean family. J Korean Med Sci 2001;16:809-813.

57. Kim JM, Shin S, Kim JY, et al. Spinocerebellar ataxia type 2 in seven Korean families: CAG trinucleotide expansion and clinical characteristics. J Korean Med Sci 1999;14:659-664.

58. Stevanin G, David G, Durr A, et al. Multiple origins of the spinocerebellar ataxia 7 (SCA7) mutation revealed by linkage disequilibrium studies with closely flanking markers, including an intragenic polymorphism (G3145TG/A3145TG). Eur J Hum Genet 1999;7:889-896.

59. Jin DK, Oh MR, Song SM, et al. Frequency of spinocerebellar ataxia types 1,2,3,6,7 and dentatorubral pallidoluysian atrophy mutations in Korean patients with spinocerebellar ataxia. J Neurol 1999;246:207-210.

60. Tan EK, Law HY, Zhao Y, et al. Spinocerebellar ataxias in Singapore: predictive features of a positive DNAtest? Eur Neurol 2000;44:168-171.

61. Monckton DG, Cayuela ML, Gould FK, et al. Very large (CAG)(n) DNA repeat expansions in the sperm of two spinocerebellar ataxia type 7 males. Hum Mol Genet 1999;8:2473-2478. 
62. Zoghbi HY, Orr HT. Polyglutamine diseases: protein cleavage and aggregation. Curr Opin Neurobiol 1999;9:566-570.

63. Cummings CJ, Orr HT, Zoghbi HY. Progress in pathogenesis of spinocerebellar ataxia type 1. Philos Trans R Soc Lond 1999;354:1079-1081.

64. Burright EN, Davidson JD, Duvick LA, Koshy B, Zoghbi HY. Identification of a self-associated region within the SCA 1 gene product, ataxin-1. Hum Mol Genet 1997;6:513-518.

65. Holmberg M, Duyckaerts C, Durr A, et al. Spinocerebellar ataxia type 7 (SCA 7): a neurodegenerative disorder with neuronal intranuclear inclusions. Hum Mol Genet 1998;7:913-918.

66. Paulson HL, Perez MK, Trottier Y, et al. Intranuclear inclusions of expanded glutamine protein in spinocerebellar ataxia type 3 . Neuron 1997;19:333-344.

67. Skinner PJ, Koshy BT, Cummings CJ, et al. Ataxin-1 with an expanded glutamine tract alters nuclear matrix-associated structures. Nature 1997;389:971-974.

68. Cummings CJ, Mancini MA, Antalffy B, et al. Chaperone suppression of aggregation and altered subcellular proteosome localization imply protein misfolding in SCA 1 . Nat Genet 1998;19:148-154.
69. Chai Y, Koppenhafer SL, Shoesmith SJ, Perez MK, Paulson HL. Evidence for proteosome involvement in polyglutamine disease: localization to nuclear inclusions in SCA3/MJD and suppression of polyglutamine in vitro. Hum Mol Genet 1999;8:673-682.

70. Klement IA, Skinner PJ, Kaytor MD, et al. Ataxin-1 nuclear localization and aggregation: role in polyglutamine-induced disease in SCA1 transgenic mice. Cell 1998;95:41-53.

71. Tan EK, Lim SH, Chan LL, Wong MC, Tan KP. X-linked adrenoleukodystrophy: spinocerebellar variant. Clin Neurol Neurosurg 1999;101:137-140.

72. Guidelines for the molecular genetics predictive test in Huntington's disease. International Huntington Association (IHA) and the World Federation of Neurology (WFN) Research Group on Huntington's chorea. Neurology 1994;44:1533-1536.

73. Botez MI, Botez-Marquard T, Mayer P, et al. The treatment of spinocerebellar ataxias: facts and hypotheses. Med Hypotheses 1998; 51:381-384.

74. Gasser T, Bressman S, Durr A, et al. State of the art review: molecular diagnosis of inherited movement disorders. Movement Disorders Society task force on molecular diagnosis. Mov Disord. 2003;18(1):3-18. 